\title{
The Toronto Empathy Questionnaire: Reliability and Validity in a Nationwide Sample of Greek Teachers
}

\author{
Ntina Kourmousi ${ }^{1, *}$, Eirini Amanaki ${ }^{2}$, Chara Tzavara ${ }^{3}$, Kyriakoula Merakou ${ }^{4}$, \\ Anastasia Barbouni ${ }^{4}$ and Vasilios Koutras ${ }^{5}$ \\ 1 Primary Education Directorate of Eastern Attica, Glyka Nera 15454, Greece \\ 2 Faculty of Primary Education, National and Kapodistrian University of Athens, Athens 10680, Greece; \\ eamanaki@primedu.uoa.gr \\ 3 Centre for Health Services Research, Department of Hygiene, Epidemiology and Medical Statistics, Medical \\ School of National and Kapodistrian University of Athens, Athens 11527, Greece; htzavara@med.uoa.gr \\ 4 National School of Public Health, 196 Alexandras Ave., Athens 11521, Greece; \\ kmerakou@esdy.edu.gr (K.M.); abarbouni@esdy.edu.gr (A.B.) \\ 5 Early Childhood Education, University of Ioannina, P.O. Box 1186, Ioannina 45110, Greece; \\ vkoutras@cc.uoi.gr \\ * Correspondence: nkourmousi@sch.gr
}

Academic Editor: Martin J. Bull

Received: 25 November 2016; Accepted: 7 June 2017; Published: 12 June 2017

\begin{abstract}
The present study examined the Toronto Empathy Questionnaire's (TEQ) validity and reliability in a sample of 3955 Greek teachers. In order to test the internal consistency reliability, the Cronbach's alpha coefficient was used and was found satisfactory at 0.72 . The sample was randomly split and an exploratory factor analysis (EFA) was conducted in the even subsample, justifying the one-factor solution, with the only discrepancy of the low loading of an item. In the odd subsample a confirmatory factor analysis (CFA) was performed to confirm the one-factor model identified by the EFA. The chi square test $\left(\chi^{2}\right)$ of the model was significant $(p<0.05)$, while the root mean square error of approximation (RMSEA), the comparative fit index (CFI) and the goodness of fit index (GFI) values were $0.078,0.969$ and 0.960 , respectively, further supporting the model's fit. Student's $t$-tests and analysis of variance (ANOVA) showed that women, teachers with children of their own, those working full-time in public schools, those with students who needed special education, and those who had received mental health promotion training, scored higher. Additionally, multiple linear regression analysis revealed that sex, working status, having students who needed special education, and having attended mental health training courses were independently associated with TEQ score. The analyses confirmed that the Greek version of TEQ could be used for researches in Greek educators as a valid and reliable measure of teachers' empathy.
\end{abstract}

Keywords: empathy; Toronto Empathy Questionnaire; TEQ; teachers/educators; reliability; validity; Greek sample

\section{Introduction}

The ability to empathize can be essential for social interactions and communication, for forming and maintaining meaningful emotional relationships, and for prosocial behavior in general. Hoffman (2008) states that empathy is "the spark of human concern for others, the glue that makes social life possible" (Hoffman 2008, p. 3). Although it is not a new concept and its importance has been demonstrated in a variety of studies from different fields (psychology, education, medicine etc.) its definition remains a subject of different or even overlapping conceptual approaches. It generally refers to being able to accurately perceive the emotional state of others and it includes the consequences that this capability has on the individual (Spreng et al. 2009). 
There are two components of empathy that are usually recognized as distinguishable in recent studies - an emotional one and a cognitive one (Baldner and McGinley 2014; Preston and De Waal 2002) - even though both seem to be interconnected and important for its expression (Hoffman 2008; Decety and Jackson 2004; Decety and Jackson 2006). Emotional empathy describes the emotional reaction (e.g., concern) towards another person's feelings (e.g., sadness) (Spreng et al. 2009; Eisenberg 2002; Eisenberg et al. 1997; Eisenberg et al. 2002) while it does not necessarily mean that the individual recognizes the reasons behind them on an intellectual level (Rankin et al. 2005). It involves another's emotional world and the individual's involvement into it, experiencing comparable feelings (Trommsdorff et al. 2007). Cognitive empathy, conversely, refers to the cognitive identification and understanding of another person's emotional state while not requiring the parallel emotional experience (Decety and Jackson 2004; Cox et al. 2012; Lawrence et al. 2004; Preston et al. 2007). In that context empathy is defined as a complex cognitive process of reaching conclusions about other people's thoughts and feelings, by using skills such as observation, memory, etc. (William 1993, 1997), much like in theory of mind. In conclusion, empathy includes both the emotional and the cognitive aspect, meaning the understanding of not only another person's feelings but of his or her thoughts and motives as well, while maintaining a sense of self (Decety and Jackson 2004; Decety and Jackson 2006; William 1993, 1997; Batson 2014; Batson et al. 1997). De Waal (De Waal 2008) includes a third dimension, the identification with the other adopting his or her perspective, whereas Decety and Jackson (Decety and Jackson 2004) support self-other distinction for maintaining the source of the emotion. A concept close but discernible to empathy according to some researchers (Rankin et al. 2005; De Waal 2008) and included in it according to others (Davis 1994), is perspective taking, which refers to the individual observing the other person's visual, auditory and situational stimuli and to understanding what he or she thinks and feels, without reacting emotionally (Rankin et al. 2005), while trying to comprehend their different perspectives and how they fit together. While this may lead to empathy it is hardly that without the emotional engagement, according to De Waal (De Waal 2008). Empathy, on the other hand, may often lead to compassion, pity and altruistic behavior (Batson 2014; De Waal 2008; Bateson 2011; Miu and Balteş 2012).

Empathy has been studied in various professional fields that involve effective communication, such as health care (Burks et al. 2012; Mohammadreza et al. 2002), sales (McBane 1995; Peterson and Limbu 2009), management (Rubina et al. 2010), and helping professions (e.g., Williams 1989; Miller et al. 1988). It has also been found to be an important trait for teachers since the relationship between teacher-student also affects the relationships between students, while enhancing the climate of the classroom and, subsequently, students' learning and academic achievements (Barr 2011; Baker 2006; Barr 2013; Birch and Ladd 1997; Hamre and Pianta 2005; Hattie 2009; Hughes et al. 2008; Liew et al. 2010; Luckner and Pianta 2011; Roorda et al. 2011). When students feel safe, welcome, at ease, supported and understood, then they can fully engage in school activities and progress in educational accomplishments (Roorda et al. 2011; Wentzel 1997; Tettegah and Anderson 2007; Raufelder et al. 2016; Demetriou and Wilson 2009; Demetriou et al. 2009; Ladd et al. 2000; Pianta and Stuhlman 2004), a fact to be taken into consideration for all educational levels. Teachers' empathy has been researched mainly regarding relations with their students and the latter's school performance (Barr 2011; Baker 2006; Barr 2013; Birch and Ladd 1997; Hamre and Pianta 2005; Hattie 2009; Hughes et al. 2008; Liew et al. 2010; Luckner and Pianta 2011; Roorda et al. 2011; Wentzel 1997; Tettegah and Anderson 2007; Raufelder et al. 2016; Demetriou and Wilson 2009; Demetriou et al. 2009; Ladd et al. 2000; Pianta and Stuhlman 2004). However, there seems to be no relevant research regarding Greek educators up to date. There has not been any empathy measure created or adapted for use in the Greek schools' teacher population either.

\subsection{Measures of Empathy}

Existing measures of empathy present differences in the conceptualization of empathy, in how many factors or subscales they include, and in the population they are targeted for. One of the 
first measures which was later doubted by Cross and Sharpley for its psychometric properties (Cross and Sharpley 1982) and by Davis who argued that it was rather a social skills assessment tool (Davis 1994), was the Hogan Empathy Scale (HES) (Hogan 1969) which consists of 64 items and supports a single factor model. Mehrabian and Epstein included more factors in the 7-dimension Questionnaire Measure of Emotional Empathy (QMEE) in 1972 (Mehrabian and Epstein 1972), which, quite later, was revised by its first author and named Balanced Emotional Empathy Scale (BEES) (Mehrabian 1996). Davis's Interpersonal Reactivity Index (IRI) (Davis 1983) also included more factors and consisted of 4 subscales: Perspective Taking, Fantasy, Empathetic Concern and Personal Distress. The first two subscales mirror the emotional and cognitive dimensions of empathy, while the two latter are not included in Baldner's, Conrad's, and McGinley's conceptualization of empathy (Baldner and McGinley 2014).

Some recent and well-received measures of empathy are the Empathy Quotient (EQ) (Baron-Cohen and Wheelwright 2004), which assesses both the emotional and the cognitive dimension of a person's perceptions about his or her empathy and was designed to measure empathy as a single factor, the Basic Empathy Scale (BES) (Jolliffe and Farrington 2006), which is intended for use in young people and adolescents and measures both dimensions of empathy, and its adaptation for adults, the Basic Empathy Scale in Adults (BES-A), which consists of three factors: emotional contagion, cognitive empathy and emotional disconnection (Carré et al. 2013).

\subsection{Toronto Empathy Questionnaire}

The Toronto Empathy Questionnaire was constructed by Spreng, McKinnon, Mar and Levine (Spreng et al. 2009) in an effort to create a self-report measure to efficiently and reliably assess empathy as an emotional process, taking into account the difficulty of an unambiguous definition and the common ground between the different concepts. The TEQ manufacturers aimed to create a tool to assess one's empathy as a central process on the broadest level (Spreng et al. 2009), which current self-report measures of empathy fail to achieve due to their great heterogeneity (William 1997), although they note that a multifaceted measure may be preferable in some situations. Through exploratory factor analysis, they identified a group of highly related items from across many measures, in order to construct a unidimensional factor of empathy (Spreng et al. 2009). Its construct validity has been demonstrated through associations with other measures of empathy (e.g., positive correlation with the EQ $r=0.80, p<0.001$ ) or similar concepts, such as interpersonal sensitivity and social comprehension. Its internal consistency was found high, ranging from $\alpha=0.85$ to $\alpha=0.87$, as well as its test-retest reliability at $r=0.81, p<0.001$ (Spreng et al. 2009).

The TEQ has been used in studies conducted in a number of different countries, such as Canada (Cusi et al. 2011; Lamothe et al. 2014; Parlar et al. 2014), United Kingdom (Brewer and Kerslake 2015; Robinson and Wright 2013), USA (Baldner and McGinley 2014), France (Lelorain et al. 2013), Turkey (Celik et al. 2013; Totan et al. 2012), Romania (Miu and Balteş 2012; Balteș and Miu 2014) and Trinidad and Tobago (Youssef et al. 2014). It has proven to be a reliable measure of empathy for different age groups with satisfactory psychometric properties: adolescents (Brewer and Kerslake 2015), university students (Baldner and McGinley 2014; Celik et al. 2013; Totan et al. 2012; Youssef et al. 2014) and adults (Cusi et al. 2011; Lamothe et al. 2014; Parlar et al. 2014; Robinson and Wright 2013; Lelorain et al. 2013). The TEQ has also been used in clinical populations assessing the empathetic responding of adults with major depressive disorder (Cusi et al. 2011) and post-traumatic stress disorder (Parlar et al. 2014), and in individuals who experienced crisis episodes (Robinson and Wright 2013). In two recent studies TEQ was chosen to investigate how empathy influences music-induced emotions (Miu and Balteş 2012; Balteș and Miu 2014), while in two others it was used to research the empathetic concern of general practitioners (physicians) (Lamothe et al. 2014; Lelorain et al. 2013). To our knowledge, the TEQ has not been used in educators' populations so far.

Regarding the validation of TEQ in different languages, there are very few studies available; we were able to identify two such studies: the one of Totan et al. on university students in Turkey 
(Totan et al. 2012) and the research of Kim and Han on undergraduate and graduate students in Korea (Han 2016). Both corroborated the psychometric properties of TEQ and offered support for the single factor model of the TEQ according to the exploratory factor analysis. The present study aims to translate the Toronto Empathy Questionnaire (Spreng et al. 2009) and investigate the reliability and construct validity of the translated version in Greek teachers.

\section{Materials and Methods}

\subsection{Procedure}

The research was conducted from December 2015 to the end of January 2016. The Scientific and Ethics committee of the Department of Early Childhood Education of the University of Ioannina approved the conduct of the survey. The study questionnaire was anonymous and it was posted for several days on the Panhellenic School Network which is the official Greek site for schools and educators to which $99.98 \%$ of elementary and secondary schools are linked (www.sch.gr), on various official sites of Greek schools' teachers' associations (i.e., www.pekade.gr, www.p-e-f.gr, www.inital.gr, etc.) and on all the important and most visited educational sites (i.e., www.specialeducation.gr, www.alfavita.gr, www.esos.gr, www.ipaideia.gr, www.omep.gr,etc.). It would appear after clicking on a banner's link asking, "Are you an educator? Would you like to know your level of empathy?" following an informative page on the study and on the questionnaire structure. Participants' consent was granted by choosing to complete the questionnaire that contained questions concerning personal and job-related information and the TEQ. Upon completion, the participants would receive their scores, together with information regarding empathy.

\subsection{Participants}

Data from 3955 subjects (1108 men and 2847 women) were analyzed. Sample characteristics are presented in Table 1. Most of them $(72.0 \%)$ were female with $43.3(\mathrm{SD}=8.9)$ years of mean age. Two out of three were married (66.4\%) and had children (66.7\%), while $35.4 \%$ of them held a Masters or a PhD. Additionally, the majority worked in the public sector $(84.6 \%)$, teaching full time $(88.1 \%)$ in a permanent position $(86.6 \%)$, with $15.5(\mathrm{SD}=8.4)$ mean teaching years. Only $12.9 \%$ of the participants were school principals and the mean years of having this position was $7.2(\mathrm{SD}=5.6)$. The mean number of students in the participants' class was $18.2(\mathrm{SD}=9.6)$. Moreover, $52.4 \%$ of the teachers had students who needed special education according to a specialist, whereas $70.3 \%$ claimed to have undiagnosed students in need of special education in their class and $63.8 \%$ reported that they had students with difficulties in speaking or language apprehension. Also, 20.6\% of the sample reported having attended training in mental health promotion.

Table 1. Sample characteristics.

\begin{tabular}{lc}
\hline & $\mathbf{N}(\mathbf{\%})$ \\
\hline Sex & \\
\hline Men & $1108(28.0)$ \\
Women & $2847(72.0)$ \\
\hline Age, mean (SD) & $43.3(8.9)$ \\
\hline Married & \\
\hline No & $1329(33.6)$ \\
Yes & $2626(66.4)$ \\
\hline Children & \\
\hline No & $1317(33.3)$ \\
Yes & $2638(66.7)$ \\
\hline
\end{tabular}


Table 1. Cont.

\begin{tabular}{|c|c|}
\hline & $\mathbf{N}(\%)$ \\
\hline \multicolumn{2}{|l|}{ Highest degree } \\
\hline Bachelor & $2552(64.5)$ \\
\hline Masters & $1216(30.7)$ \\
\hline $\mathrm{PhD}$ & $187(4.7)$ \\
\hline Years of teaching, mean (SD) & $15.5(8.4)$ \\
\hline \multicolumn{2}{|l|}{ Number of residents in the area of teaching } \\
\hline At most 1999 & $442(11.2)$ \\
\hline 2000 to 9999 & $833(21.1)$ \\
\hline 10,000 to 250,000 & $1916(48.4)$ \\
\hline More than 250,000 & $764(19.3)$ \\
\hline \multicolumn{2}{|l|}{ School } \\
\hline Public & $3344(84.6)$ \\
\hline Private & $611(15.4)$ \\
\hline \multicolumn{2}{|l|}{ Working status } \\
\hline Part time & $471(11.9)$ \\
\hline Full time & $3484(88.1)$ \\
\hline \multicolumn{2}{|l|}{ In case of working in public sector: } \\
\hline Substitute teacher & $437(13.4)$ \\
\hline Permanent teacher & $2833(86.6)$ \\
\hline \multicolumn{2}{|l|}{ Principal } \\
\hline No & $3443(87.1)$ \\
\hline Yes & $512(12.9)$ \\
\hline Years of serving as principal, mean (SD) & $7.2(5.6)$ \\
\hline Number of students in class, mean (SD) & $18.2(9.6)$ \\
\hline \multicolumn{2}{|c|}{ Students in need of special education (according to a specialist) } \\
\hline No & $1881(47.6)$ \\
\hline Yes & $2074(52.4)$ \\
\hline \multicolumn{2}{|l|}{$\begin{array}{l}\text { Students in need of special education (according to own } \\
\text { opinion) }\end{array}$} \\
\hline No & $1174(29.7)$ \\
\hline Yes & $2781(70.3)$ \\
\hline \multicolumn{2}{|l|}{ Students with difficulties in speaking or apprehension } \\
\hline No & $1431(36.2)$ \\
\hline Yes & $2524(63.8)$ \\
\hline $\begin{array}{l}\text { If yes, how many, median (IQR) } \\
\text { Having received training on mental health promotion }\end{array}$ & $2(2-4)$ \\
\hline No & $3141(79.4)$ \\
\hline Yes & $814(20.6)$ \\
\hline
\end{tabular}

\subsection{Measures}

\subsubsection{Empathy}

The Toronto Empathy Questionnaire (TEQ) (Spreng et al. 2009) was chosen to measure sample teachers' empathy. It consists of 16 items that are scored on a 5-point Likert scale, as follows: $0=$ Never, $1=$ Rarely, 2 = Sometimes, 3 = Often, $4=$ Always. It covers a broad range of typical characteristics associated with the emotional dimension of empathy. Its questions include emotional contagion (e.g., 
"When someone else is feeling excited, I tend to get excited too"), emotion comprehension (e.g., "I can tell when others are sad even when they do not say anything"), sympathetic physiological arousal (e.g., "It upsets me to see someone being treated disrespectfully") and con-specific altruism (e.g., "When I see someone being taken advantage of, I feel kind of protective towards him/her"). Eight items $(2,4,7,10,11,12,14,15)$ are reversed. Scores are summed to derive total for the TEQ, which can range from 0 to 64 , with high scores indicating higher levels of empathy.

\subsubsection{Translation}

The TEQ was translated into the Greek language from the original questionnaire following translation protocols (Solano-Flores et al. 2009; Van de Vijver and Hambleton 1996). Two professional translators, native speakers of the Greek language (i.e., target) and fluent in the English language (i.e., source) proceeded with independent forward translations into the target language. A preliminary Greek version was developed which was then translated back into the original language by another professional translator. These two English versions, the back-translation and the original scale, were then compared; if any discrepancies were found between the two, adjustments were made to produce the final Greek version presented in the Appendix A.

\subsubsection{Demographic Information}

In a cross sectional study design personal data were collected, such as age, sex, family status, number of children, educational level, and having received training in mental health promotion. Work-related information was also collected, such as the type of educational setting (private or public), the years of teaching experience, the working status (part-time or full-time), the permanence of position, the number of students in class, the number of students in need of special education etc.

\section{Statistical Analysis}

Continuous variables are presented with mean and standard deviation (SD). Qualitative variables are presented with absolute and relative frequencies. The sample was randomly split into two datasets of approximately equal size. Data of the even subsample $(\mathrm{N}=1997)$ were used to carry out an exploratory factor analysis in order to evaluate construct validity of the questionnaire. The cut-off point for factor loadings was 0.40 . A confirmatory factor analysis (CFA) with maximum likelihood procedure was performed in the odd subsample $(\mathrm{N}=1958)$ in order to confirm the model identified from the EFA. The variance of the latent constructs was fixed at one during parameter estimation. The fit of the CFA model was assessed using the chi square $\left(\chi^{2}\right)$, the comparative fit index (CFI), the goodness of fit index (GFI) and the root mean square error of approximation (RMSEA) (Mueller 2000). For the CFI and GFI indices, values close to or greater than 0.95 are taken to reflect a good fit to the data (Hu and Bentler 1999). RMSEA values of less than 0.05 indicate a good fit and values as high as 0.08 indicate a reasonable fit ( $\mathrm{Hu}$ and Bentler 1999). Also, a non-significant chi square statistic indicates a good fit, but chi square is usually sensitive to sample sizes and usually significant for large sample sizes (Mueller 2000). The internal consistency of the questionnaire was analyzed with Cronbach's $\alpha$. Reliability equal to or greater than 0.70 was considered acceptable. Multiple linear regression analyses in a stepwise method ( $p$ for removal was set at 0.1 and $p$ for entry was set at 0.05 ) was performed in order to find variables independently associated with TEQ total score. All demographics and job related characteristics were added in the initial regression model. Regressions coefficients with their standard errors were computed from the results of the regression analyses. Also, coefficient of determination $\left(\mathrm{R}^{2}\right)$ was reported as a measure of variation that is explained by the model. $P$ values reported are two-tailed. Statistical significant level was set at 0.05 and analysis was conducted using SPSS and AMOS (SPSS, Chicago, IL, USA) Statistical Software. 


\section{Results}

Descriptive statistics for the TEQ items are shown in Table 2. The higher median value was 4 and was found for the items $3,5,7,12,14,15$, and 16 .

Table 2. Descriptive statistics for the TEQ items.

\begin{tabular}{|c|c|c|c|c|c|}
\hline & Mean & SD & Median & Percentile 25 & Percentile 75 \\
\hline $\begin{array}{l}\text { 1. When someone else is feeling excited, I tend to get } \\
\text { excited too. }\end{array}$ & 2.5 & 0.8 & 3 & 2 & 3 \\
\hline 2. Other people's misfortunes do not disturb me a great deal. & 2.6 & 1.2 & 3 & 2 & 4 \\
\hline 3. It upsets me to see someone being treated disrespectfully. & 3.6 & 0.7 & 4 & 3 & 4 \\
\hline 4. I remain unaffected when someone close to me is happy. & 3.3 & 0.8 & 3 & 3 & 4 \\
\hline 5. I enjoy making other people feel better. & 3.6 & 0.6 & 4 & 3 & 4 \\
\hline $\begin{array}{l}\text { 6. I have tender, concerned feelings for people less fortunate } \\
\text { than me. }\end{array}$ & 3.2 & 0.8 & 3 & 3 & 4 \\
\hline $\begin{array}{l}\text { 7. When a friend starts to talk about his } \backslash \text { her problems, I try to steer } \\
\text { the conversation towards something else. }\end{array}$ & 3.5 & 0.7 & 4 & 3 & 4 \\
\hline $\begin{array}{l}\text { 8. I can tell when others are sad even when they do not say } \\
\text { anything. }\end{array}$ & 3.1 & 0.8 & 3 & 3 & 4 \\
\hline 9. I find that I am "in tune" with other people's moods. & 2.6 & 0.7 & 3 & 2 & 3 \\
\hline $\begin{array}{l}\text { 10. I do not feel sympathy for people who cause their own serious } \\
\text { illnesses. }\end{array}$ & 2.9 & 1 & 3 & 2 & 4 \\
\hline 11. I become irritated when someone cries. & 2.9 & 1 & 3 & 2 & 4 \\
\hline 12. I am not really interested in how other people feel. & 3.5 & 0.8 & 4 & 3 & 4 \\
\hline $\begin{array}{l}\text { 13. I get a strong urge to help when I see someone who } \\
\text { is upset. }\end{array}$ & 3.3 & 0.8 & 3 & 3 & 4 \\
\hline $\begin{array}{l}\text { 14. When I see someone being treated unfairly, I do not feel very } \\
\text { much pity for them. }\end{array}$ & 3.5 & 0.9 & 4 & 3 & 4 \\
\hline 15. I find it silly for people to cry out of happiness. & 3.6 & 0.7 & 4 & 3 & 4 \\
\hline $\begin{array}{l}\text { 16. When I see someone being taken advantage of, I feel kind } \\
\text { of protective towards him } \backslash \text { her. }\end{array}$ & 3.4 & 0.8 & 4 & 3 & 4 \\
\hline
\end{tabular}

Note: Items in italics are reversed; percentiles indicate the score below which the given percentage of sample may be found.

A principal components analysis was performed in the even subsample. The EFA performed by restricting it to a single factor, produced a Kaiser Meier Olkin (KMO) coefficient equal to 0.83 and a Barlett $\chi^{2}$ value equal to $7321.5(p<0.001)$. The proportion of total variance explained was $20.6 \%$. The factor loading of the item 11 was equal to 0.20 and below the criterion of 0.40 . When the corrected item total correlations were examined, the value of item 11 was low and equal to 0.15 . Therefore, the aforementioned item was omitted from the questionnaire. The results of the EFA performed without the item 11, showed a Kaiser Meier Olkin (KMO) coefficient equal to 0.83 and a Barlett $\chi^{2}$ value equal to $7098.5(p<0.001)$. The proportion of total variance explained was $22 \%$. Factor loadings (Table 3) ranged from 0.40 (item 8 and item 14) to 0.67 (item 13). Corrected item-total correlations and Cronbach's alpha if an item was deleted are presented in Table 3. Internal consistency reliability for the TEQ in the total sample was accepted with Cronbach's alpha equal to 0.72. Afterwards, a CFA was conducted in the odd subsample to estimate if the model fitted the data well. The CFA indicated an adequate fit of the one-factor model (RMSEA $=0.078, \mathrm{CFI}=0.969$ and GFI $=0.960)$. None of the item cross loadings exceeded the item loadings on the intended latent construct. The chi-square test of the model was significant $(p<0.05)$. Cronbach's alpha was equal to 0.73 and 0.71 for the even and the odd subsample, respectively. 
Table 3. Factor loadings from the results of exploratory factor analysis, inter-item correlation coefficients and internal consistency reliability of the TEQ questionnaire.

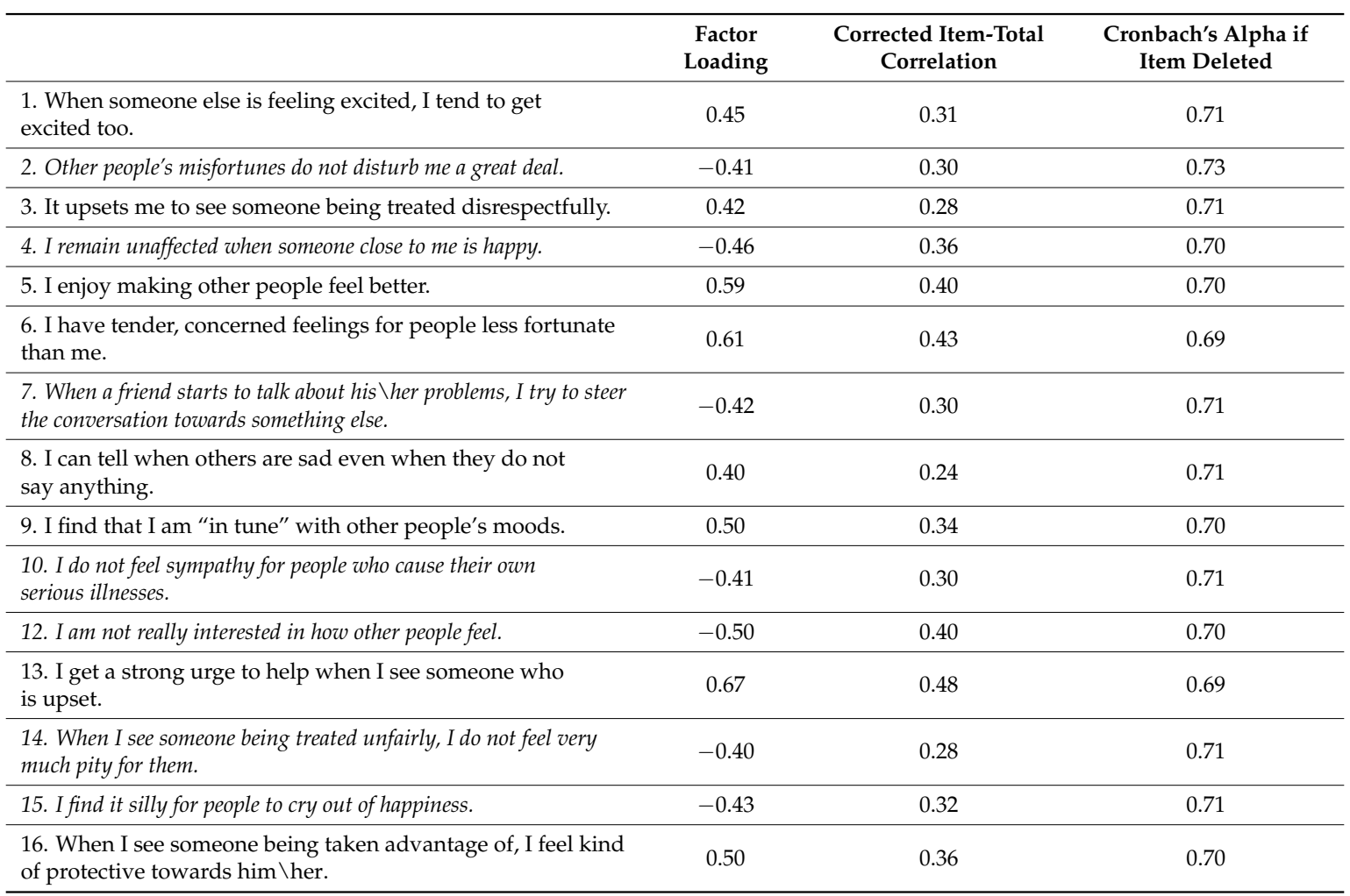

The mean TEQ score was $3.2(\mathrm{SD}=0.4)$.

When multiple regression analysis was performed in a stepwise method, it was found that sex, working status, the presence of students in need of special education and mental health promotion training were independently associated with TEQ score (Table 4). The R2 of the model was equal to 0.05. Specifically, greater scores were found in women, in those that worked full time, in those who had students in need of special education in their class and in those who had received training in mental health promotion.

Table 4. Results from multiple linear regression analysis in a stepwise method with the TEQ score as the dependent variable $(\mathrm{N}=3955)$.

\begin{tabular}{lcc}
\hline & $\beta$ (SE) & $p$ \\
\hline Sex & & \\
\hline $\begin{array}{l}\text { Men, reference } \\
\text { Women }\end{array}$ & $0.16(0.01)$ & $<0.001$ \\
\hline Working status & & \\
\hline $\begin{array}{l}\text { Part time, reference } \\
\text { Full time }\end{array}$ & $0.04(0.02)$ & 0.049 \\
\hline $\begin{array}{l}\text { Students in need of special education (according to own opinion) } \\
\quad \begin{array}{l}\text { No, reference } \\
\text { Yes }\end{array}\end{array}$ & $0.03(0.01)$ & 0.017 \\
\hline Having received training in mental health promotion & & \\
\hline $\begin{array}{l}\text { No, reference } \\
\text { Yes }\end{array}$ & $0.05(0.01)$ & $<0.001$ \\
\hline
\end{tabular}

Regression coefficient (Standard Error). 


\section{Discussion}

Empathy has been researched extensively for many decades and holds a continued interest in a variety of different fields, even though there are diverse conceptualizations and, consequently, definitions (Baldner and McGinley 2014). The main purpose of the present study was to investigate the Toronto Empathy Questionnaire (Spreng et al. 2009) translated version's reliability and construct validity, in Greek teachers. Firstly, the EFA performed in the even subsample was restricted to one factor that explained $20.6 \%$ of the variance. Item 11 ("I become irritated when someone cries") loaded below the criterion of 0.40 , even when the corrected item-total correlations were examined; therefore it was excluded from the questionnaire. The EFA without the item 11 accounted for $22 \%$ of the variance. Such exclusions can sometimes be found in validations of measures in other languages or in other groups (e.g., Ypofanti et al. 2015; Egan et al. 2016).

Factor loadings ranged from 0.40 to 0.67 , a finding in accordance with the factor loadings of the original questionnaire (Spreng et al. 2009). The confirmatory factor analysis performed in the odd subsample indeed corroborated the unidimensional model by Spreng et al. (2009) and proved to be an adequate fit for the data. Specifically, the RMSEA value was 0.078 , whereas the CFI and GFI values were 0.969 and 0.960 , respectively. The chi-square test of the model was significant, a predicted finding due to our large sample size (Mueller 2000). There is a lack of validation studies in different languages as far as the TEQ is concerned. We managed to identify two such studies; in the first, a research on Turkish university students (Totan et al. 2012), researchers were also able to sufficiently replicate the one-factor model, although the manufacturers advise caution that some situations may require a multi-faceted construct (Spreng et al. 2009). In the other one, a study on Korean graduate students (Han 2016), the researchers claimed that according to the confirmatory factor analysis there lacked a goodness of fit in the single factor model, while according to the exploratory factor analysis the single factor was suggested. In our study, the internal consistency reliability of the TEQ was satisfactory at $\alpha=0.72$, comparable to the one reported by the manufacturers (Spreng et al. 2009) and by other researchers (Baldner and McGinley 2014; Robinson and Wright 2013; Celik et al. 2013; Totan et al. 2012; Balteș and Miu 2014; Youssef et al. 2014). Taking into account that TEQ is scored on a scale from 0 to 4 , the mean score $3.2(\mathrm{SD}=0.4)$ found in our study suggests that our sample reported rather high levels of empathy or, in any case, higher than the mean score reported in the original questionnaire (Spreng et al. 2009).

Multiple regression analysis revealed that sex, working status, the presence of students in need of special education and the training in mental health promotion could predict the empathy of Greek educators; however, the R2 of the model was low. Specifically, women scored higher in the TEQ, supporting similar findings that females tend to exhibit higher empathy than males (Spreng et al. 2009; Totan et al. 2012; Balteș and Miu 2014; Youssef et al. 2014; Toussaint and Webb 2005; Turnage et al. 2012). These sex differences do not emerge in all empathy studies however, prompting Baldner and McGinley (Baldner and McGinley 2014) to state that self-report measures of empathy do not vastly differentiate among genders. It could be hypothesized that the variant findings reflect the divergence in empathy conceptualization, but also the many interpersonal and intrapersonal factors that come into play. Age and years of teaching did not correlate with the TEQ, indicating that empathy does not change over the years in Greek educators due to maturity, neither gets altered by teaching experience, unlike skills such as problem solving (Kourmousi et al. 2016) and locus of control (Kourmousi et al. 2015).

Multiple regression analysis further revealed that greater scores were found in teachers who worked full time. We can only hypothesize that the limited days or months part-time teachers spend with one class prevents them from engaging in deep relationships with their students, either because they cannot afford the time, or simply because they prefer to keep it that way since they know that they will soon have to work somewhere else. The presence of students in need of special education also seemed to affect self-reported empathy in Greek educators; the ones who had such students performed better in the TEQ. Empathy's association with interpersonal sensitivity could explain those teachers' higher levels of empathy on TEQ. Lastly, teachers who had received mental health promotion training also exhibited higher self-reported empathy according to the multiple regression analysis; this finding 
was somewhat expected since active listening is often an important part of such training programs (Kaminski et al. 2008; Ragozzino et al. 2003).

\section{Strengths and Limitations}

The main strengths of the present study are the large sample of contributing educators and their diversity concerning their specialty, the grade they taught, the years of teaching experience and the geographical areas in which they worked Furthermore, the percentage of the study participants' representation concerning sex, mean age, mean working years, working status, teaching grade, specialty, and geographical region, was identical with the one presented by the Greek Statistical Authority concerning educators of the 2015-2016 academic year (Greek Statistical Authority 2016). That, together with the facts that (a) all Greek school units are officially linked to the Panhellenic School Network on the site of which our study was posted and (b) all Greek regions were represented accordingly, can characterize our sample as representative. In addition, we were able to confirm the good fit of TEQ, a short and homogenous construct, to a Greek sample. We should stress though, that since the Greek version approximately approached the original one, with the exception of one item which was found to have a low loading and was excluded, we suggest that future researchers should administer it in whole but omit this item in the scoring procedure.

Other limitations can also be identified. Given that the design of the study was cross-sectional, we were not able to examine the TEQ's sensitivity over time or its test-retest reliability. Furthermore, the convergent validity of the TEQ was not tested, since another similar scale validated for adults in Greece does not yet exist. Another weakness of this study which was conducted via internet is the possibility of participants having completed a questionnaire more than once.

\section{Conclusions}

In conclusion, the TEQ can be applied to Greek educators' populations with good construct validity and internal consistency for evaluating empathy adding support for its easy utilization, not only in the educational community but in the adult population in general. However, more studies concerning teachers' empathy and tools that measure it should be conducted in Greece, in order to identify reinforcing factors, especially those that could be enhanced. Further investigation of the role of mental health promotion training should also be realized. Finally, validation studies conducted in other countries would help in the investigation of the TEQ's reliability and validity in other languages as well.

Acknowledgments: We would like to thank the Panhellenic School Network, all the official sites of Greek educators' associations, and the Greek educational sites for hosting our questionnaire. We would especially like to thank all the teachers who contributed significantly to our study by taking the time to complete our online questionnaire.

Author Contributions: N.K. conceived, designed and conducted the study, with the help of V.K., K.M., and A.B. C.T. analyzed the data. E.A. drafted the manuscript, and together with the other authors reviewed its final form.

Conflicts of Interest: The authors declare no conflict of interest.

\section{Appendix A}

Greek Translation of the Toronto Empathy Questionnaire

1. 'О

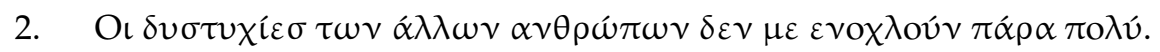

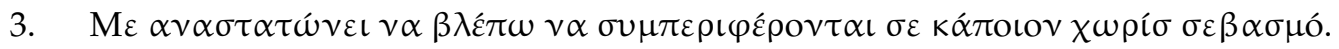

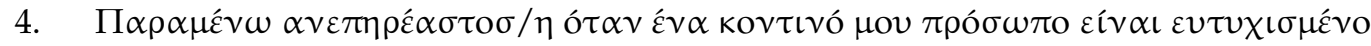

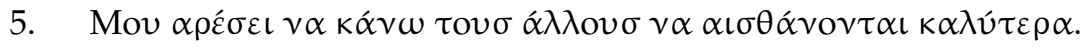

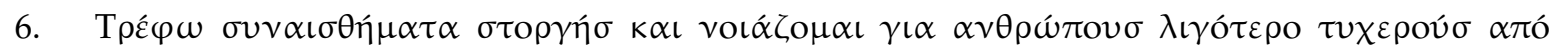
$\varepsilon \mu \varepsilon \varepsilon \mathcal{\varepsilon} \alpha$.

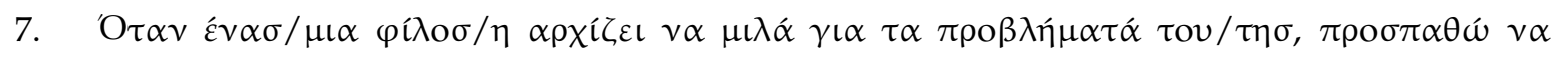

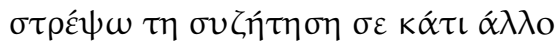




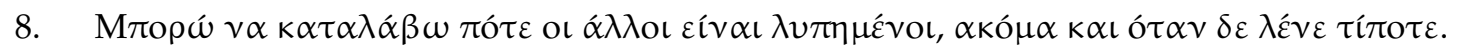

9. $\Theta \varepsilon \omega \rho \omega ́$ ó

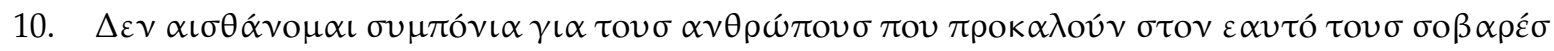

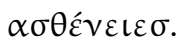

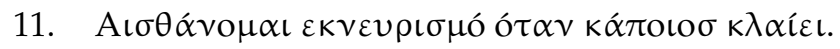

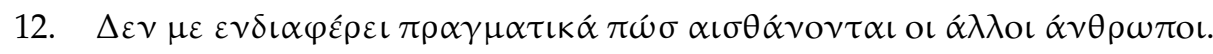

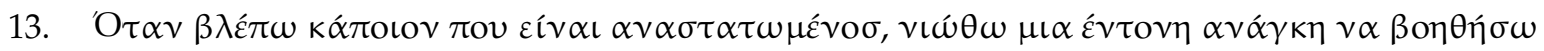

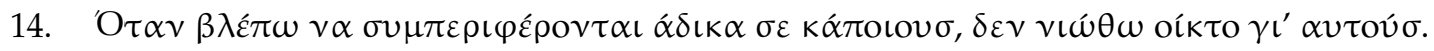

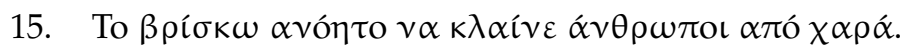

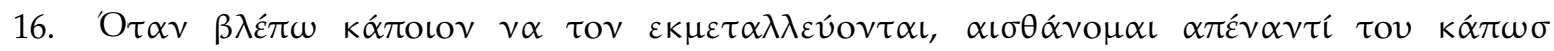
$\pi \rho 0 \sigma \tau \alpha \tau \varepsilon v \tau$ เ $\alpha \dot{~}$

Note: Permission to use the Greek translation of the TEQ is granted for educational purposes only, upon request. We suggest that the scale should be administered as presented, but exclude the 11th item from the scoring procedure.

\section{Abbreviations}

$\begin{array}{ll}\text { ANOVA } & \text { Analysis Of Variance } \\ \text { CFA } & \text { Confirmatory Factor Analysis } \\ \text { CFI } & \text { Comparative Fit Index } \\ \text { EFA } & \text { Exploratory Factor Analysis } \\ \text { GFI } & \text { Goodness of Fit Index } \\ \text { RMSEA } & \text { Root Mean Square Error of Approximation } \\ \text { TEQ } & \text { Toronto Empathy Questionnaire } \\ \chi^{2} & \text { chi square }\end{array}$

\section{References}

Baker, Jean A. 2006. Contributions of teacher-child relationships to positive school adjustment during elementary school. Journal of School Psychology 44: 211-29. [CrossRef]

Balteș, Felicia Rodica, and Andrei C. Miu. 2014. Emotions during live music performance: Links with individual differences in empathy, visual imagery, and mood. Psychomusicology: Music, Mind, and Brain 24: 58-65. [CrossRef]

Baron-Cohen, Simon, and Sally Wheelwright. 2004. The empathy quotient: An investigation of adults with Asperger syndrome or high functioning autism, and normal sex differences. Journal of Autism and Developmental Disorders 34: 163-75. [CrossRef] [PubMed]

Barr, Jason J. 2011. The relationship between teachers' empathy and perceptions of school culture. Educational Studies 37: 365-69. [CrossRef]

Barr, Jason J. 2013. Student-teachers' attitudes toward students with disabilities: Associations with contact and empathy. International Journal of Education and Practice 1: 87-100.

Bateson, Daniel C. 2011. These Things called Empathy: Eight Related but Distinct Phenomena. In The Social Neuroscience of Empathy. Edited by Jean Decety and William Ickes. Cambridge: MIT Press, pp. 3-15.

Batson, Daniel C. 2014. The Altruism Question: Toward a Social-Psychological Answer. New York: Psychology Press.

Batson, Daniel C., Karen Sager, Eric Garst, Misook Kang, Kostia Rubchinsky, and Karen Dawson. 1997. Is empathy-induced helping due to self-other merging? Journal of Personality and Social Psychology 73: 495-509. [CrossRef]

Birch, Sondra H., and Gary W. Ladd. 1997. The teacher-child relationship and children's early school adjustment. Journal of School Psychology 35: 61-79. [CrossRef]

Brewer, Gayle, and John Kerslake. 2015. Cyberbullying, self-esteem, empathy and loneliness. Computers in Human Behavior 48: 255-60. [CrossRef]

Burks, Derek J., Lorraine K. Youll, and Jayson P. Durtschi. 2012. The empathy-altruism association and its relevance to health care professions. Social Behavior and Personality: An International Journal 40: 395-400. [CrossRef] 
Carré, Arnaud, Nicolas Stefaniak, Fanny D'Ambrosio, Leïla Bensalah, and Chrystel Besche-Richard. 2013. The Basic Empathy Scale in Adults (BES-A): Factor structure of a revised form. Psychological Assessment 25: 679-91. [CrossRef] [PubMed]

Celik, Kazim, Emel Saritas, and Gulsum Catalbas. 2013. The Effect of Student Teachers' Liking of Children and Empathic Tendency on the Attitudes of Teaching Profession. International Journal Social Sciences and Education 3: 499-510.

Baldner, Conrad, and Jared J. McGinley. 2014. Correlational and exploratory factor analyses (EFA) of commonly used empathy questionnaires: New insights. Motivation and Emotion 38: 727-44. [CrossRef]

Cox, Christine L., Lucina Q. Uddin, Adriana Di Martino, F. Xavier Castellanos, Michael P. Milham, and Clare Kelly. 2012. The balance between feeling and knowing: Affective and cognitive empathy are reflected in the brain's intrinsic functional dynamics. Social Cognitive and Affective Neuroscience 7: 727-37. [CrossRef] [PubMed]

Cross, Darryl G., and C. F. Sharpley. 1982. Measurement of empathy with the Hogan Empathy Scale. Psychological Reports 50: 62. [CrossRef]

Cusi, Andrée M., Grenda M. MacQueen, R. Nathan Spreng, and Margaret C. McKinnon. 2011. Altered empathic responding in major depressive disorder: Relation to symptom severity, illness burden, and psychosocial outcome. Psychiatry Research 188: 231-36. [CrossRef] [PubMed]

Davis, Mark H. 1983. Measuring individual differences in empathy: Evidence for a multidimensional approach. Journal of Personality and Social Psychology 44: 113-26. [CrossRef]

Davis, Mark H. 1994. Empathy: A Social Psychological Approach. Boulder: Westview Press.

De Waal, Frans B. M. 2008. Putting the altruism back into altruism: The evolution of empathy. Annual Review of Psychology 59: 279-300. [CrossRef] [PubMed]

Decety, Jean, and Philip L. Jackson. 2004. The functional architecture of human empathy. Behavioral and Cognitive Neuroscience Reviews 3: 71-100. [CrossRef] [PubMed]

Decety, Jean, and Philip L. Jackson. 2006. A social-neuroscience perspective on empathy. Current Directions in Psychological Science 15: 54-58. [CrossRef]

Demetriou, Helen, and Elaine Wilson. 2009. Synthesising affect and cognition in teaching and learning. Social Psychology of Education 12: 213-32. [CrossRef]

Demetriou, Helen, Elaine Wilson, and Mark Winterbottom. 2009. The role of emotion in teaching: Are there differences between male and female newly qualified teachers' approaches to teaching? Educational Studies 35: 449-73. [CrossRef]

Egan, Sarah J., Roz Shafran, Michelle Lee, Christopher G. Fairburn, Zafra Cooper, Helen A. Doll, Robert L. Palmer, and Hunna J. Watson. 2016. The reliability and validity of the clinical perfectionism questionnaire in eating disorder and community samples. Behavioural and Cognitive Psychotherapy 44: 79-91. [CrossRef]

Eisenberg, Nancy. 2002. Empathy-related emotional responses, altruism, and their socialization. In Visions of Compassion: Western Scientists and Tibetan Buddhists Examine Human Nature. Edited by Anne Harrington and Richard J. Davidson. New York: Oxford University Press, pp. 131-64.

Eisenberg, Nancy, Richard A. Fabes, Stephanie A. Shepard, Brisget C. Murphy, Ivanna K. Guthrie, Sarah Jones, Jo Friedman, Rick Poulin, and Pat Maszk. 1997. Contemporaneous and longitudinal prediction of children's social functioning from regulation and emotionality. Child Development 68: 642-64. [CrossRef] [PubMed]

Eisenberg, Nancy, Ivanna K. Guthrie, Amanda Cumberland, Bridget C. Murphy, Stephanie A. Shepard, Qing Zhou, and Gustavo Carlo. 2002. Prosocial development in early adulthood: A longitudinal study. Journal of Personality and Social Psychology 82: 993-1006. [CrossRef] [PubMed]

Greek Statistical Authority. 2016. Greece in Figures. Athens: Directorate of Statistical Information and Publications, Available online: http:/ / www.statistics.gr/documents/20181/1515741/GreeceInFigures_2016Q4_GR.pdf/ bed1542a-d54d-4cf0-b06e-bdd01c1125ac (accessed on 20 March 2017). (In Greek)

Hamre, Bridget K., and Robert C. Pianta. 2005. Can instructional and emotional support in the first-grade classroom make a difference for children at risk of school failure? Child Development 76: 949-67. [CrossRef] [PubMed]

Han, Hwan Sumi Kim. 2016. A Validation Study of the Toronto Empathy Questionnaire-Korean Version. Korean Journal of Clinical Psychology 35: 809-21.

Hattie, John A. C. 2009. Visible Learning: A Synthesis of 800+ Meta-Analyses on Achievement. Abingdon: Routledge. Hoffman, Martin L. 2008. Empathy and prosocial behavior. In Handbook of Emotions, 3rd Edition. Edited by Michael Lewis, Jeannette M. Haviland-Jones and Lisa Feldman Barrett. New York: Guilford Press, pp. 440-55. 
Hogan, Robert. 1969. Development of an empathy scale. Journal of Consulting and Clinical Psychology 33: 307-16. [CrossRef] [PubMed]

$\mathrm{Hu}$, Litze, and Peter M. Bentler. 1999. Cutoff criteria for fit indexes in covariance structure analysis: Conventional criteria versus new alternatives. Structural Equation Modeling: A Multidisciplinary Journal 6: 1-55. [CrossRef]

Hughes, Jan N., Wen Luo, Oi-Man Kwok, and Linda K. Loyd. 2008. Teacher-student support, effortful engagement, and achievement: A 3-year longitudinal study. Journal of Educational Psychology 100: 1-14. [CrossRef] [PubMed]

Jolliffe, Darrick, and David P. Farrington. 2006. Development and validation of the Basic Empathy Scale. Journal of Adolescence 29: 589-611. [CrossRef] [PubMed]

Kaminski, Jennifer Wyatt, Linda Anne Valle, Jill H. Filene, and Cynthia L. Boyle. 2008. A meta-analytic review of components associated with parent training program effectiveness. Journal of Abnormal Child Psychology 36: 567-89. [CrossRef] [PubMed]

Kourmousi, Ntina, Vasiliki Xythali, and Vasilios Koutras. 2015. Reliability and validity of the multidimensional locus of control IPC scale in a sample of 3668 Greek educators. Social Sciences 4: 1067-78. [CrossRef]

Kourmousi, Ntina, Vasiliki Xythali, Maria Theologitou, and Vasilios Koutras. 2016. Validity and Reliability of the Problem Solving Inventory (PSI) in a Nationwide Sample of Greek Educators. Social Sciences 5: 25. [CrossRef]

Ladd, Gary W., Eric S. Buhs, and Michael Seid. 2000. Children's initial sentiments about kindergarten: Is school liking an antecedent of early classroom participation and achievement? Merrill-Palmer Quarterly 46: 255-79.

Lamothe, Martin, Emilie Boujut, Franck Zenasni, and Serge Sultan. 2014. To be or not to be empathic: The combined role of empathic concern and perspective taking in understanding burnout in general practice. BMC Family Practice 15: 1. [CrossRef] [PubMed]

Lawrence, E. J., Philip Shaw, Dawn Baker, Simon Baron-Cohen, and Antony S. David. 2004. Measuring empathy: Reliability and validity of the Empathy Quotient. Psychological Medicine 34: 911-20. [CrossRef] [PubMed]

Lelorain, Sophie, Serge Sultan, Franck Zenasni, Annie Catu-Pinault, Philippe Jaury, Emilie Boujut, and Laurent Rigal. 2013. Empathic concern and professional characteristics associated with clinical empathy in French general practitioners. The European Journal of General Practice 19: 23-28. [CrossRef] [PubMed]

Liew, Jeffrey, Qi Chen, and Jan N. Hughes. 2010. Child effortful control, teacher-student relationships, and achievement in academically at-risk children: Additive and interactive effects. Early Childhood Research Quarterly 25: 51-64. [CrossRef] [PubMed]

Luckner, Amy E., and Robert C. Pianta. 2011. Teacher-student interactions in fifth grade classrooms: Relations with children's peer behavior. Journal of Applied Developmental Psychology 32: 257-66. [CrossRef]

McBane, Donald A. 1995. Empathy and the salesperson: A multidimensional perspective. Psychology E Marketing 12: 349-70.

Mehrabian, Albert. 1996. Manual for the Balanced Emotional Empathy Scale (BEES). Menterrey: Albert Mehrabian.

Mehrabian, Albert, and Norman Epstein. 1972. A measure of emotional empathy. Journal of Personality 40: 525-43. [CrossRef] [PubMed]

Miller, Katherine I., James B. Stiff, and Beth Hartman Ellis. 1988. Communication and empathy as precursors to burnout among human service workers. Communications Monographs 55: 250-65. [CrossRef]

Miu, Andrei C., and Felicia Rodica Balteş. 2012. Empathy manipulation impacts music-induced emotions: A psychophysiological study on opera. PLoS ONE 7: e30618. [CrossRef]

Mohammadreza, Hojat, Joseph S. Gonnella, Thomas J. Nasca, Salvatore Mangione, Michael Vergare, and Michael Magee. 2002. Physician empathy: Definition, components, measurement, and relationship to gender and specialty. American Journal of Psychiatry 159: 1563-69.

Mueller, Ralph O. 2000. Basic Principles of Structural Equation Modelling. New York: Springer.

Parlar, Melissa, Paul Frewen, Anthony Nazarov, Carolina Oremus, Grenda MacQueen, Ruth Lanius, and Margaret C. McKinnon. 2014. Alterations in empathic responding among women with posttraumatic stress disorder associated with childhood trauma. Brain and Behavior 4: 381-89. [CrossRef] [PubMed]

Peterson, Robin T., and Yam Limbu. 2009. The convergence of mirroring and empathy: Communications training in business-to-business personal selling persuasion efforts. Journal of Business-to-Business Marketing 16: 193-219. [CrossRef]

Pianta, Robert C., and Megan W. Stuhlman. 2004. Teacher-child relationships and children's success in the first years of school. School Psychology Review 33: 444-59.

Preston, Stephanie D., and Frans B. M. De Waal. 2002. Empathy: Its ultimate and proximate bases. Behavioral and Brain Sciences 25: 1-20. [CrossRef] [PubMed] 
Preston, Stephanie D., Antoine Bechara, Hanna Damasio, Thomas J. Grabowski, R. Brent Stansfield, Sonya Mehta, and Antonio R. Damasio. 2007. The neural substrates of cognitive empathy. Social Neuroscience 2: 254-75. [CrossRef] [PubMed]

Ragozzino, Katharine, Hank Resnik, Mary Utne-O'Brien, and Roger P. Weissberg. 2003. Promoting academic achievement through social and emotional learning. Educational Horizons 81: 169-71.

Rankin, Katherine P., Joel H. Kramer, and Bruce L. Miller. 2005. Patterns of cognitive and emotional empathy in frontotemporal lobar degeneration. Cognitive and Behavioral Neurology 18: 28-36. [CrossRef] [PubMed]

Raufelder, Diana, Lisa Nitsche, Sven Breitmeyer, Sabrina Keßler, Elisa Herrmann, and Nicola Regner. 2016. Students' perception of "good" and "bad" teachers-Results of a qualitative thematic analysis with German adolescents. International Journal of Educational Research 75: 31-44. [CrossRef]

Robinson, Oliver C., and Gordon R. T. Wright. 2013. The prevalence, types and perceived outcomes of crisis episodes in early adulthood and midlife: A structured retrospective-autobiographical study. International Journal of Behavioral Development 37: 407-16. [CrossRef]

Roorda, Debora L., Helma H. M. Koomen, Jantine L. Spilt, and Frans J. Oort. 2011. The influence of affective teacher-student relationships on students' school engagement and achievement a meta-analytic approach. Review of Educational Research 81: 493-529. [CrossRef]

Rubina, Mahsud, Gary Yukl, and Greg Prussia. 2010. Leader empathy, ethical leadership, and relations-oriented behaviors as antecedents of leader-member exchange quality. Journal of Managerial Psychology 25: 561-77.

Solano-Flores, Guillermo, Eduardo Backhoff, and Luis Ángel Contreras-Niño. 2009. Theory of Test Translation Error. International Journal of Testing 9: 78-91. [CrossRef]

Spreng, Nathan R., Margaret McKinnon, Raymond A. Mar, and Brian Levine. 2009. The Toronto Empathy Questionnaire: Scale development and initial validation of a factor-analytic solution to multiple empathy measures. Journal of Personality Assessment 91: 62-71. [CrossRef] [PubMed]

Tettegah, Sharon, and Carolyn J. Anderson. 2007. Pre-service teachers' empathy and cognitions: Statistical analysis of text data by graphical models. Contemporary Educational Psychology 32: 48-82. [CrossRef]

Totan, Tarik, Tayfun Dogan, and Fatma Sapmaz. 2012. The Toronto Empathy Questionnaire: Evaluation of Psychometric Properties among Turkish University Students. Eurasian Journal of Educational Research 46: 179-98.

Toussaint, Loren, and Jon R. Webb. 2005. Gender differences in the relationship between empathy and forgiveness. The Journal of Social Psychology 145: 673-85. [CrossRef] [PubMed]

Trommsdorff, Gisela, Wolfgang Friedlmeier, and Boris Mayer. 2007. Sympathy, distress, and prosocial behavior of preschool children in four cultures. International Journal of Behavioral Development 31: 284-93. [CrossRef]

Turnage, Barbara F., Young Joon Hong, Andre P. Stevenson, and Beverly Edwards. 2012. Social work students' perceptions of themselves and others: Self-esteem, empathy, and forgiveness. Journal of Social Service Research 38: 89-99. [CrossRef]

Van de Vijver, Fons, and Ronald K. Hambleton. 1996. Translating tests: Some practical guidelines. European Psychologist 1: 89-99. [CrossRef]

Wentzel, Kathryn R. 1997. Student motivation in middle school: The role of perceived pedagogical caring. Journal of Educational Psychology 89: 411-19. [CrossRef]

William, Ickes. 1993. Empathic accuracy. Journal of Personality 61: 587-610.

William, Ickes. 1997. Empathic Accuracy. New York: Guilford Press.

Williams, Carol A. 1989. Empathy and burnout in male and female helping professionals. Research in Nursing $\mathcal{E}$ Health 12: 169-78.

Youssef, Farid F., Paula Nunes, Bidyadhar Sa, and Stella Williams. 2014. An exploration of changes in cognitive and emotional empathy among medical students in the Caribbean. International Journal of Medical Education 5: 185-92. [CrossRef] [PubMed]

Ypofanti, Maria, Vasiliki Zisi, Nikolaos Zourbanos, Barbara Mouchtouri, Pothiti Tzanne, Yannis Theodorakis, and Georgios Lyrakos. 2015. Psychometric properties of the International Personality Item Pool Big-Five personality questionnaire for the Greek population. Health Psychology Research 3: 2206. [CrossRef] [PubMed]

(C) 2017 by the authors. Licensee MDPI, Basel, Switzerland. This article is an open access article distributed under the terms and conditions of the Creative Commons Attribution (CC BY) license (http:/ / creativecommons.org/licenses/by/4.0/). 